\title{
Salivary Levels of IL-21 as a Potential Marker of Stage III Grade C Periodontitis
}

\author{
Ayse Ege Selman ${ }^{1}\left(\right.$, Nimet Gul Gorgulu ${ }^{2}$, Basak Dogan ${ }^{1}$ \\ ${ }^{1}$ Department of Periodontology, Faculty of Dentistry, Marmara University, Istanbul, Turkey. \\ ${ }^{2}$ Department of Periodontology, Institute of Health Sciences, Marmara University, Istanbul, Turkey. \\ Correspondence Author: Basak Dogan \\ E-mail: basakdogan@marmara.edu.tr \\ Received: $01.09 .2021 \quad$ Accepted: 20.09.2021
}

\begin{abstract}
Objective: The onset, severity and progression of periodontal diseases are mainly related to the inflammatory host response against periodontal pathogens. The aim of this study was to evaluate salivary interleukin (IL) - 1 , IL-13, IL-21 and IL-33 levels in patients with stage III grade C periodontitis and compare it with periodontally healthy individuals.

Methods: A total of 58 individuals, including 28 periodontally healthy and 30 stage III grade C periodontitis patients were included in this study. Periodontal parameters including plaque index, gingival index, bleeding on probing, probing depth and clinical attachment level were measured. Saliva samples were obtained from all patients. Salivary interleukin (IL) - 1 $\beta$, IL-13, IL21, IL-33 levels were assessed using enzymelinked immunosorbent assay.

Results: All clinical parameters were significantly higher in periodontitis patients compared to healthy individuals $(p<0.001)$. Elevated salivary IL-1 $\beta$ and IL-21 levels were found in the periodontitis group compared to healthy ones ( $p=0.009$ and $p<0.001$, respectively). However, IL- 13 and IL-33 levels were similar in both groups $(p=0.92)$. IL-1 $\beta$ was significantly correlated with both clinical and biochemical parameters but IL-21 was correlated with only clinical parameters.

Conclusion: This study showed that elevated salivary IL-21 and IL-1 $\beta$ levels are associated with periodontitis and might be used as a marker for the diagnosis of periodontitis.
\end{abstract}

Keywords: Periodontitis, interleukin-1 beta, interleukin-13, interleukin-21, interleukin-33

\section{INTRODUCTION}

Periodontitis is a common infectious condition with the presence of gingival inflammation, alveolar bone resorption, and attachment loss (1). Host response against pathogenic microorganisms in dental biofilm is a main factor for pathogenesis of periodontitis (2). Cytokines are the messenger molecules between cells that regulate this response. Moreover, dysregulated production of cytokines is associated with the initiation and progression of several infective and inflammatory diseases such as periodontitis (24). Cytokines can act antagonistically or synergistically and are classified according to their functions as pro-inflammatory or anti-inflammatory molecules (3). The pro-inflammatory cytokine IL-1ß, act as a critical mediator of inflammation and tissue destruction. It plays a vital role in regulating inflammatory and immunological events, such as leukocyte chemotaxis, monocyte/macrophage activation, production of matrix metalloproteinases (MMPs), prostaglandins and $T$ cell activation (5). Elevated levels of IL-1ß were detected in saliva, serum, gingival crevicular fluid (GCF) and gingival tissue of patients with periodontitis (6-8).

Anti-inflammatory cytokines promote physiological health by stimulating the protective antibodies production and diminishing the levels of destructive inflammatory cytokines $(9,10)$. IL-13 is an anti-inflammatory cytokine activated by T helper 2 cells (Th2) (11). It has been shown that IL-13 inhibits pro-inflammatory cytokine synthesis and osteoclastogenesis $(12,13)$. Although, there are several studies about IL-13 levels in GCF and serum, there is no study that compares the salivary levels of IL-13 in both healthy and periodontitis groups. Miranda et al. showed similar serum IL-13 levels in both periodontally healthy and periodontitis patients (14). On the other hand, Elabdeen et al. found lower plasma IL13 levels in aggressive periodontitis patients compared to the healthy controls (15). In GCF, Gorgun et al. showed lower IL-13 levels in aggressive periodontitis patients than chronic periodontitis and periodontally healthy groups (16). Moreover, three studies have evaluated IL-13 levels in 
periodontitis before and after periodontal treatment. While two of these studies found significantly elevated GCF IL-13 levels after treatment $(16,17)$, the other showed no change (18).

IL-21 is predominantly released by Th17 cells and acts as a pro-inflammatory cytokine. It targets a broad range of immune cells $(19,20)$. A growing body of evidence shows that T-cell responses associated with inflammation and tissue destruction are improved by IL-21 (21-25). Moreover, it suppresses the production of the anti-inflammatory IL-13 cytokine produced by Th2 cells (26). There is a bidirectional activating relationship between IL-21 and IL-1ß. While IL-1 $\beta$ increases IL-21 secretion by inducing Th17 cells, IL-21 has the ability to upregulate IL-1 $\beta$ (27-29). There are limited and contradictory results regarding IL-21 levels in periodontitis compared to healthy controls. A study showed elevated salivary IL-21 levels in periodontitis compared to healthy controls (30). However, Gumus et al. found no difference in serum or salivary IL-21 levels between groups (31).

IL-33 plays a crucial role in inflammation. Since IL-33 has an effect on both increasing Th2 derived anti-inflammatory cytokines and stimulating mast cell degranulation or production of pro-inflammatory cytokines, it acts as an immunoregulator $(32,33)$. Although, elevated salivary levels of IL-33 in periodontitis patients compared to healthy controls has been reported (31), there are also studies that revealed no difference between these groups in saliva and GCF $(34,35)$.

The objective of the study was to compare the salivary IL-1 $\beta$, IL-13, IL-21, and IL-33 levels in patients with stage III grade C periodontitis and healthy controls.

\section{METHODS}

\subsection{Study Population}

A total of 58 individuals (29 male and 29 female) were recruited from the Department of Periodontology, Faculty of Dentistry, Marmara University, Istanbul, Turkey. A medical and dental histories were recorded. All individuals were systemically healthy, non-smoker, aged over 20 years and had at least 20 teeth (except third molars). The individuals that were included in the study met the following criteria; they were not pregnant or lactating, had not received periodontal treatment and were not using any antibiotics, immunosuppressive or nonsteroidal anti-inflammatory drugs in the past 6 months.

The participants were categorized into healthy or stage III grade $\mathrm{C}$ periodontitis groups according to the consensus report of the 2017 World Workshop on the Classification of Periodontal and Peri-Implant Diseases and Conditions (36). The periodontally healthy group was defined as presence of intact periodontium, no sites with attachment loss and radiographic evidence of alveolar bone loss, no history of periodontitis, bleeding on probing (BOP) $<10 \%$, probing depth $(P D)<3 \mathrm{~mm}$, while stage III periodontitis patients had at least 4 interdental sites clinical attachment level $(C A L)>5$ $\mathrm{mm}$ due to periodontitis, radiographic bone loss reaching to the mid-third of the root or beyond, teeth loss less than 4 teeth due to periodontitis.

Grade assessment was carried out according to the ratio between radiographic bone loss (\%) and age. Since the bone loss (\%)/age values were $>1.0$, all periodontitis patients were defined as grade $\mathrm{C}$.

The clinical research ethics committee of Marmara University, Faculty of Medicine, Istanbul, approved the present study protocol (12.06.2020/ 09.2020.652). All patients were informed about the study, and a written informed consent form in compliance with the 1964 Helsinki Declaration and its later amendments was obtained.

\subsection{Clinical Measurements}

A single calibrated examiner (NGG) carried out a full mouth periodontal examination of all participants. Before clinical measurements, intra-examiner calibration was performed by measuring PD and CAL values twice on five patients with one day interval resulting in intraclass correlation coefficients were 0.92 for PD and 0.90 for CAL.

Plaque index (PI) (37), gingival index (GI) (38), BOP, PD, CAL measurements were recorded at six sites of each tooth except third molars. All clinical values were examined using a UNC15 probe (Hu-Friedy, Chicago, IL). Self-reports of the patients were used as a basis for assessing existing tooth loss due to periodontitis.

\subsection{Collection and Analyses of Salivary Samples}

Unstimulated saliva samples were collected from all individuals a day after clinical measurements. All samples were obtained between $9 \mathrm{am}$ and $10 \mathrm{am}$ to decrease the effect of circadian rhythm on biomarker levels. The participants were asked not to brush their teeth, floss, chew gum, eat or drink within the last 3 hours. During saliva collection, they were requested to accumulate the saliva in the mouth for $5 \mathrm{~min}$ and spit into sterile $2 \mathrm{ml}$ Eppendorf tubes (Safe-Lock Tubes $1.5 \mathrm{ml}$, Sigma, Hamburg). Then all saliva samples were stored immediately at $-80^{\circ} \mathrm{C}$ before assays.

Salivary concentrations of IL-1 $\beta$, IL-13, IL-21 and IL-33 were determined using specific ELISA kits (Elabscience, Houston, TX, USA and Bioassay Technology Laboratory, Shanghai, China). The manufacturer's guidelines were followed for each assay, using saliva samples. The minimum detection thresholds for IL-1ß, IL-13, IL-21 and IL-33 were $4.69 \mathrm{pg} / \mathrm{mL}$, $0.2 \mathrm{ng} / \mathrm{L}, 2.46 \mathrm{ng} / \mathrm{L}$ and $2.61 \mathrm{ng} / \mathrm{L}$, respectively.

\subsection{Statistical Analyses}

The minimum sample size was determined based on a study investigating salivary IL-1 $\beta$ levels in a similar group design (39). This analysis indicated that the minimum required 
sample size was 14 for each group at $\alpha=0.05$ significance level and with a power of $90 \%$.

All statistical analyses were assessed using a statistical software package (SPSS 22.0 for Windows, Chicago, IL). Descriptive statistics such as median, minimum-maximum, mean and standard deviation values were used to present age, gender distribution, clinical and biochemical data. Difference in gender distribution was analyzed by Chisquare test. Normality analyzes of all data were performed using Kolmogorov Smirnov test. Intergroup comparisons were carried by either Students' t-test or Mann Whitney $U$ test, depending normality of the distribution. Correlations between clinical and biochemical parameters were determined by Spearman rank correlation test. For testing the possible utility of IL-1 $\beta$ and IL-21 in periodontitis diagnosis, receiver operating characteristics (ROC) and area under the curve (AUC) analyses were constructed. Statistical significance was accepted as $p<0.05$.

\section{RESULTS}

Demographic variables are presented in Table 1. The median age and gender distribution were similar in both groups $(p=0.103$ and $p=0.525$, respectively). Significantly higher values of clinical periodontal measurements were detected in the periodontitis group compared to periodontally healthy ones $(p<0.001)$ (Table 2$)$.

Table 1. Age and gender distribution pattern of healthy individuals and periodontitis patients

\begin{tabular}{|cccccc|}
\hline & & $\begin{array}{c}\text { Healthy } \\
\mathbf{N}=\mathbf{2 8}\end{array}$ & $\begin{array}{c}\text { Periodontitis } \\
\mathbf{N}=\mathbf{3 0}\end{array}$ & $\boldsymbol{p}^{*}$ & $\boldsymbol{p}^{* *}$ \\
\hline Age & Median & 31.00 & 35.50 & & \\
& $\begin{array}{c}\text { Min-Max } \\
\text { (Mean+SD) }\end{array}$ & $\begin{array}{c}23-48 \\
(33.50 \pm 7.63)\end{array}$ & $\begin{array}{c}25-59 \\
(36.23 \pm 7.94)\end{array}$ & 0.103 & \\
\hline Gender & Female & $15(53.6)$ & $14(46.7)$ & & \\
N (\%) & Male & $13(46.4)$ & $16(53.3)$ & 0.599 \\
\hline
\end{tabular}

SD: Standart Deviation. ${ }^{*}$ Mann Whitney-U test, ${ }^{* *}$ Chi-square test; $p<0.05$

The saliva levels of IL-1 $\beta$, IL-13, IL-21, IL-33 in both groups are shown in Table 3. Elevated salivary levels of IL-21 and IL-1 $\beta$ were found in the periodontitis group compared to the periodontal health ( $p<0.001$ and $p=0.009$, respectively). However, saliva IL-13 and IL-33 levels did not differ between healthy and periodontitis groups ( $p=0.932$ and $p=0.926$, respectively).

Correlations of salivary interleukin levels with clinical periodontal parameters and with each other are presented in Table 4. IL-1 $\beta$ levels correlated positively with both clinical and biochemical parameters $(p<0.01$ or $p<0.05)$ but IL-21 levels only with all clinical parameters $(p<0.01)$. Moreover, positive correlation was found between IL-13 and IL-33 $(p<0.01)$.
AUC values and ROC curves for IL-1 $\beta$ and IL-21 in discriminating periodontitis patients from healthy controls are shown in Figure 1. IL-1 $\beta$ and IL-21 provided larger AUC values than 0.5 (0.699 and 0.937, respectively).

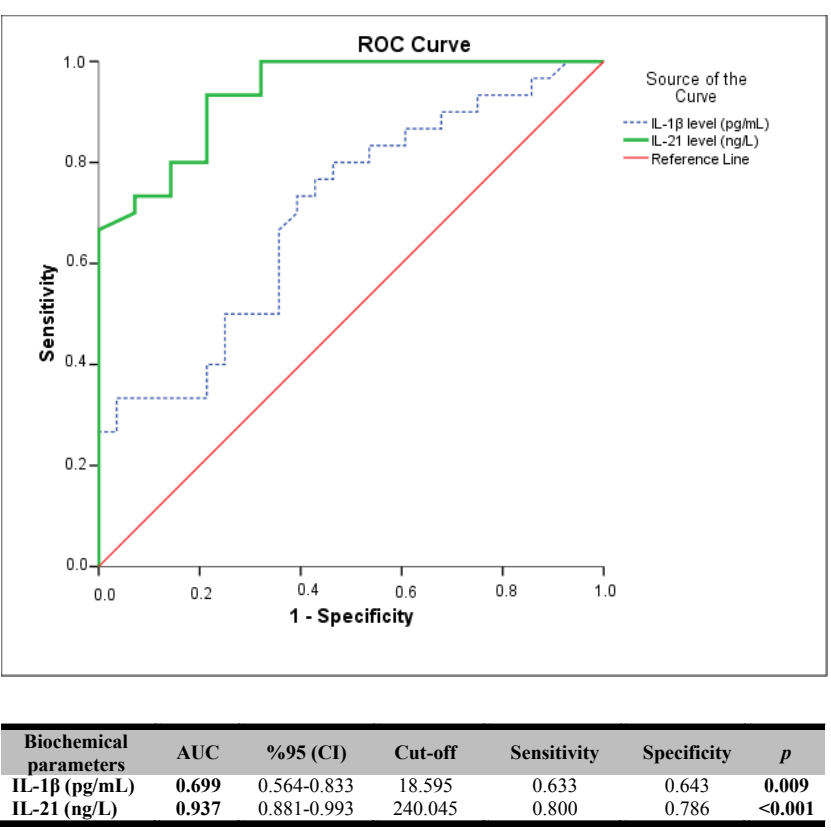

Figure 1. Receiver operating characteristics (ROC) curve of IL-16 and IL-21 in regard to periodontitis with area under the curve (AUC), 95\% confidence intervals, cut off, sensitivity, specificity and $p$ values.

Table 2. Clinical Measurements of Study Groups

\begin{tabular}{|c|c|c|c|}
\hline Periodontal Parameters & $\begin{array}{c}\text { Healthy } \\
\text { N=28 } \\
\text { Median } \\
\text { Min-Max } \\
\text { (Mean+SD) }\end{array}$ & $\begin{array}{l}\text { Periodontitis } \\
\quad \mathrm{N}=30 \\
\text { Median } \\
\text { Min-Max } \\
\text { (Mean+SD) }\end{array}$ & $p$ \\
\hline PI & $\begin{array}{c}0.11 \\
0.01-0.33 \\
(0.12 \pm 0.07) \\
\end{array}$ & $\begin{array}{c}1.85 \\
1.05-3.39 \\
(1.88 \pm 0.51) \\
\end{array}$ & $<0.001^{*}$ \\
\hline GI & $\begin{array}{c}0.07 \\
0.01-0.18 \\
(0.06 \pm 0.04)\end{array}$ & $\begin{array}{c}1.90 \\
0.41-2.22 \\
(1.75 \pm 0.46)\end{array}$ & $<0.001^{*}$ \\
\hline BOP (\%) & $\begin{array}{c}5.75 \\
1.19-10.50 \\
(6.11 \pm 2.52) \\
\end{array}$ & $\begin{array}{c}93.64 \\
20.51-100 \\
(82.24 \pm 23.45)\end{array}$ & $<0.001^{*}$ \\
\hline PD (mm) & $\begin{array}{c}1.91 \\
1.52-2.32 \\
(1.91 \pm 0.16)\end{array}$ & $\begin{array}{c}4.28 \\
3.12-5.82 \\
(4.30 \pm 0.63)\end{array}$ & $<0.001^{\sharp}$ \\
\hline CAL (mm) & $\begin{array}{c}1.92 \\
1.52-2.32 \\
(1.93 \pm 0.17)\end{array}$ & $\begin{array}{c}4.76 \\
3.22-5.99 \\
(4.73 \pm 0.69)\end{array}$ & $<0.001^{\sharp}$ \\
\hline
\end{tabular}

SD: Standart Deviation; PI: Plaque Index; GI: Gingival Index; BOP: Bleeding on Probing; PD: Probing Depth; CAL: Clinical Attachment Level. "Mann Whitney-U test, "Student's t-test; $p<0.05$ 
Table 3. Saliva Levels of Interleukins in Study Groups

\begin{tabular}{|c|c|c|c|}
\hline $\begin{array}{l}\text { Biochemical } \\
\text { Parameters }\end{array}$ & 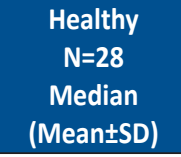 & $\begin{array}{l}\text { Periodontitis } \\
\qquad \begin{array}{c}\mathrm{N}=\mathbf{3 0} \\
\text { Median } \\
\text { (Mean } \pm \mathrm{SD})\end{array}\end{array}$ & $p^{*}$ \\
\hline IL-1 $\beta$ (pg/mL) & $\begin{array}{c}10.02 \\
2.32-61.62 \\
18.17 \pm 16.40\end{array}$ & $\begin{array}{c}26.30 \\
2.37-368.56 \\
54.91 \pm 76.09\end{array}$ & 0.009 \\
\hline IL-13 (ng/L) & $\begin{array}{c}18.79 \\
11.01-23.65 \\
17.76 \pm 3.82\end{array}$ & $\begin{array}{c}18.12 \\
9.82-23.13 \\
17.86 \pm 3.43\end{array}$ & 0.932 \\
\hline IL-21 (ng/L) & $\begin{array}{c}200.78 \\
127.65-255.01 \\
197.33 \pm 37.76\end{array}$ & $\begin{array}{c}261.49 \\
223.37-312.65 \\
265.43 \pm 24.73\end{array}$ & $<0.001$ \\
\hline IL-33 (ng/L) & $\begin{array}{c}319.99 \\
121.92-466.96 \\
300.14 \pm 82.77\end{array}$ & $\begin{array}{c}303.76 \\
140.64-433.81 \\
306.72 \pm 65.59\end{array}$ & 0.926 \\
\hline
\end{tabular}

SD-Standart deviation. *Mann Whitney-U test; $p<0.05$

Table 4. Correlation of Biochemical and Clinical Parameters

\begin{tabular}{|c|c|c|c|c|c|}
\hline & & $\mathrm{IL}-1 \beta(\mathrm{pg} / \mathrm{mL})$ & IL-13 (ng/L) & IL-21 (ng/L) & $\begin{array}{c}\text { IL-33 } \\
\text { (ng/L) }\end{array}$ \\
\hline PI & $r$ & $0.326^{*}$ & 0.090 & $0.668^{* *}$ & 0.104 \\
\hline GI & $r$ & $0.406^{* *}$ & 0.050 & $0.684^{* *}$ & -0.011 \\
\hline PD & $r$ & $0.407^{* *}$ & 0.139 & $0.679^{* *}$ & 0.126 \\
\hline CAL & $r$ & $0.414^{* *}$ & 0.161 & $0.677^{* *}$ & 0.167 \\
\hline BOP (\%) & r & $0.406^{* *}$ & 0.062 & $0.716^{* *}$ & 0.054 \\
\hline IL-1 $\beta$ (pg/mL) & r & - & $0.612^{* *}$ & $0.441^{* *}$ & $0.455^{* *}$ \\
\hline IL-13 (ng/L) & r & & - & 0.210 & $0.837^{* *}$ \\
\hline IL-21 (ng/L) & $r$ & & & - & 0.228 \\
\hline
\end{tabular}

PI: plaque index; GI: gingival index; BOP: bleeding on probing; PD: probing depth; CAL: clinical attachment level, r: Correlation coefficient. Spearman's Rank Correlation Test; ${ }^{*} p<0.05,{ }^{*} p<0.01$

\section{DISCUSSION}

The present study is the first study that investigated salivary IL-1 $\beta$, IL-13, IL-21 and IL-33 levels in patients with stage III grade $C$ periodontitis and healthy controls. Various cytokines have been studied in the literature to understand the hostmediated nature of peridontitis. Although, periodontitis is diagnosed according to the clinical measurements and radiographic findings, these parameters do not provide information about disease activity and early diagnosis. Thus, it is important to explore a reliable biomarker of periodontal tissue destruction with high specificity, sensitivity and utility (40).

Periodontal diseases are associated with increased levels of particular pro-inflammatory cytokines in saliva due to repeated insult of dental biofilms (41-43). IL-1 $\beta$ is a proinflammatory cytokine that involves in inflammation, immune regulation and bone resorption in periodontitis. Considered number of studies showed the well-established role of IL-1 $\beta$ in pathogenesis of periodontitis $(6,7)$. In line with earlier findings, the present study resulted in significantly higher salivary IL-1 $\beta$ levels in patients with periodontitis compared to healthy ones $(6,7)$. Furthermore, $I L-1 \beta$ is a strong biomarker in discriminating periodontitis patients from periodontally healthy individuals with its high AUC value (0.699). The positive relation between clinical parameters and IL-1 $\beta$ found in the present study supports the knowledge about the pathogenic role of IL-1 $\beta$ in periodontitis.

Levels of anti-inflammatory cytokines are expected to be lower in periodontitis than healthy individuals (10). Unexpectedly, in the present study, the salivary levels of IL13, an anti-inflammatory cytokine did not differ between groups. To our knowledge, there is no study available regarding to the salivary IL-13 levels in periodontal health or disease. Future studies are needed to better understand its role in periodontitis.

In an in vitro study, it was shown that IL-1 $\beta$ enhances Th2 differentiation and IL-13 production (44). In accordance with this study, the positive relation was found between IL-1 $\beta$ and IL-13 in the present study. However, future studies are needed to establish the relationship.

IL-21 is a pro-inflammatory cytokine that affects the functions of various immune cells and exaggerates the host-immune response. It involves the development of Th17 cells and suppresses the Th2 cell differentiation and function $(26,45$, 46). Thus, IL-21 have a critical function in the pathogenesis of periodontal disease. The present findings demonstrated elevated salivary IL-21 levels in periodontitis compared to healthy individuals $(p<0.001)$. In accordance with present results, several studies showed higher IL-21 levels in periodontitis $(30,46,47)$. Similar to our findings, Lokhande et al. found higher serum and salivary IL-21 levels in patients with periodontitis than healthy controls (30). Dutzan et al. found overexpressed IL-21 in periodontitis-affected tissues than healthy ones (47). Since cytokines that highly expressed in gingival tissues during inflammation, are spilled over eventually to saliva, this finding may explain the higher salivary levels of this interleukin. On the other hand, a single study revealed similar IL-21 levels between periodontitis and healthy controls (31). Furthermore, the diagnostic accuracy of IL-21 was found to be good in the present study with its high AUC value (0.937). Thus, IL-21 can be an important mediator for periodontal disease. The positive and significant correlation between IL-21 and IL-1 $\beta$ levels seen here may be attributable to the fact that IL-21 upregulates the IL-1 $\beta$ expression and IL-1 $\beta$ stimulates IL-21 production, as mentioned earlier (27-29). Although, IL-1 $\beta$ is a well-known biomarker that differentiates health and disease, there are very limited data on the role of IL-21 in periodontitis. Our results demonstrated that IL-21 might be a crucial marker for the diagnosis of periodontitis similarly to IL-1 $\beta$.

Early evidence demonstrated that IL-33 is released from damaged endothelial cells and functions as an alarmin. It induces the production of anti-inflammatory cytokines like IL-13 as a result of stimulating Th2 cells, but at the same time it increases mast cell degranulation and the synthesis 
of pro-inflammatory cytokines such as IL-1 $\beta(32,33)$. Results of the present study revealed similar salivary IL-33 levels in both healthy and periodontitis patients which is consistent with other studies by Saglam et al. (34) and Buduneli et al. (35). However, Gumus et al. found elevated salivary IL-33 levels in periodontitis group compared to healthy individuals (31). Moreover, in an experimental animal study higher expression was found in periodontitis compared to healthy ones (48). Future studies are needed to understand its role in periodontitis.

There was a positive relation between IL-33 and IL-1 $\beta$. The positive relation between salivary IL-33 and IL-1 $\beta$ levels supports the knowledge about the inductive effect of IL-33 on mast cell degranulation and therefore, IL-1 $\beta$ production (33). Furthermore, we found positive relation between IL33 and IL-13. This finding may be explained by the inductive effect of IL-33 on Th2 cells and IL-13 mentioned before (32).

The limitations of the present study were investigation of the cytokines in a single body fluid and a cross-sectional study design.

\section{CONCLUSIONS}

In conclusion, IL-21 levels like IL-1 $\beta$, were detected higher in the periodontitis patients than healthy ones suggesting a crucial role in periodontitis pathogenesis. Follow-up studies including different body fluids like GCF and/or serum, are needed to confirm that IL-21 could be used as a salivary biomarker of peridontitis.

\section{REFERENCES}

[1] Armitage GC. Development of a classification system for periodontal diseases and conditions. Ann Periodontol 1999;4:1-6.

[2] Cekici A, Kantarci A, Hasturk H, Van Dyke TE. Inflammatory and immune pathways in the pathogenesis of periodontal disease. Periodontol 2000 2014;64:57-80.

[3] Dinarello CA. Historical insights into cytokines. Eur J Immunol 2007;37 Suppl 1:S34-45.

[4] Teles R, Moss K, Preisser JS, Genco R, Giannobile WV, Corby P, Garcia N, Jared H, Torresyap G, Salazar E, Moya J, Howard C, Schifferle R, Falkner KL, Gillespie J, Dixon D, Cugini M. Patterns of periodontal disease progression based on linear mixed models of clinical attachment loss. J Clin Periodontol 2018;45:15-25.

[5] Barksby HE, Lea SR, Preshaw PM, Taylor JJ. The expanding family of interleukin-1 cytokines and their role in destructive inflammatory disorders. Clin Exp Immunol 2007;149:217-225.

[6] Kc S, Wang XZ, Gallagher JE. Diagnostic sensitivity and specificity of host-derived salivary biomarkers in periodontal disease amongst adults: Systematic review. J Clin Periodontol 2020;47:289-308.

[7] Gumus P, Nizam N, Nalbantsoy A, Ozcaka O, Buduneli N. Saliva and serum levels of pentraxin-3 and interleukin-1beta in generalized aggressive or chronic periodontitis. J Periodontol 2014;85:e40-46.
[8] Medara N, Lenzo JC, Walsh KA, Reynolds EC, Darby IB, O’BrienSimpson NM. A review of Thelper 17 cell-related cytokines in serum and saliva in periodontitis. Cytokine 2021;138:155340.

[9] Yamazaki K, Nakajima T. Antigen specificity and T-cell clonality in periodontal disease. Periodontol 2000 2004;35:75-100.

[10] Pradeep AR, Roopa Y, Swati PP. Interleukin-4, a T-helper 2 cell cytokine, is associated with the remission of periodontal disease. J Periodontal Res 2008;43:712-716.

[11] Jakubzick C, Kunkel SL, Puri RK, Hogaboam CM. Therapeutic targeting of IL-4 - and IL-13-responsive cells in pulmonary fibrosis. Immunol Res 2004;30:339-349.

[12] Palmqvist $P$, Lundberg $P$, Persson E, Johansson A, Lundgren I, Lie A, Conaway HH, Lerner UH. Inhibition of hormone and cytokine-stimulated osteoclastogenesis and bone resorption by interleukin- 4 and interleukin- 13 is associated with increased osteoprotegerin and decreased RANKL and RANK in a STAT6dependent pathway. J Biol Chem 2006;281:2414-2429.

[13] Minty A, Chalon P, Derocq JM, Dumont X, Guillemot JC, Kaghad M, Labit C, Leplatois P, Liauzun P, Miloux B. Interleukin-13 is a new human lymphokine regulating inflammatory and immune responses. Nature 1993;362:248-250.

[14] Miranda TS, Heluy SL, Cruz DF, da Silva HDP, Feres M, Figueiredo LC, Duarte PM. The ratios of pro-inflammatory to antiinflammatory cytokines in the serum of chronic periodontitis patients with and without type 2 diabetes and/or smoking habit. Clin Oral Investig 2019;23:641-650.

[15] Zein Elabdeen HR, Mustafa M, Ali R, Bolstad Al. Cytokine profile in gingival crevicular fluid and plasma of patients with aggressive periodontitis. Acta Odontol Scand 2017;75:616622.

[16] Gorgun EP, Toker H, Tas A, Alpan AL, Sari I, Silig Y. IL-13 gene polymorphisms $(-1112 \mathrm{C} / \mathrm{T}$ and $-1512 \mathrm{~A} / \mathrm{C})$ in patients with chronic and aggressive periodontitis: Effects on GCF and outcome of periodontal therapy. Niger J Clin Pract 2021;24:965-972.

[17] Al-Hamoudi N, Alsahhaf A, Al Deeb M, Alrabiah M, Vohra $\mathrm{F}$, Abduljabbar T. Effect of scaling and root planing on the expression of anti-inflammatory cytokines (IL-4, IL-9, IL-10, and IL-13) in the gingival crevicular fluid of electronic cigarette users and non-smokers with moderate chronic periodontitis. J Periodontal Implant Sci 2020;50:74-82.

[18] Emingil G, Gurkan A, Atilla G, Kantarci A. Subantimicrobialdose doxycycline and cytokine-chemokine levels in gingival crevicular fluid. J Periodontol 2011;82:452-461.

[19] Brandt K, Singh PB, Bulfone-Paus S, Ruckert R. Interleukin-21: a new modulator of immunity, infection, and cancer. Cytokine Growth Factor Rev 2007;18:223-232.

[20] Gharibi T, Majidi J, Kazemi T, Dehghanzadeh R, Motallebnezhad $M$, Babaloo Z. Biological effects of IL-21 on different immune cells and its role in autoimmune diseases. Immunobiology 2016;221:357-367.

[21] Lubberts E. Th17 cytokines and arthritis. Semin Immunopathol 2010;32:43-53.

[22] Beklen A, Ainola M, Hukkanen M, Gurgan C, Sorsa T, Konttinen YT. MMPs, IL-1, and TNF are regulated by IL-17 in periodontitis. J Dent Res 2007;86:347-351.

[23] Allam JP, Duan Y, Heinemann F, Winter J, Gotz W, Deschner J, Wenghoefer M, Bieber T, Jepsen S, Novak N. IL-23-producing CD68(+) macrophage-like cells predominate within an IL17-polarized infiltrate in chronic periodontitis lesions. J Clin Periodontol 2011;38:879-886. 
[24] Adibrad M, Deyhimi P, Ganjalikhani Hakemi M, Behfarnia P, Shahabuei M, Rafiee L. Signs of the presence of Th17 cells in chronic periodontal disease. J Periodontal Res 2012;47:525531.

[25] Dutzan N, Konkel JE, Greenwell-Wild T, Moutsopoulos NM. Characterization of the human immune cell network at the gingival barrier. Mucosal Immunol 2016;9:1163-1172.

[26] Lin PY, Jen HY, Chiang BL, Sheu F, Chuang YH. Interleukin-21 suppresses the differentiation and functions of $\mathrm{T}$ helper 2 cells. Immunology 2015;144:668-676.

[27] Moutsopoulos NM, Kling HM, Angelov N, Jin W, Palmer RJ, Nares S, Osorio M, Wahl SM. Porphyromonas gingivalis promotes Th17 inducing pathways in chronic periodontitis. J Autoimmun 2012;39:294-303.

[28] Maddur MS, Miossec P, Kaveri SV, Bayry J. Th17 cells: biology, pathogenesis of autoimmune and inflammatory diseases, and therapeutic strategies. Am J Pathol 2012;181:8-18.

[29] Tahmasebinia F, Pourgholaminejad A. The role of Th17 cells in auto-inflammatory neurological disorders. Prog Neuropsychopharmacol Biol Psychiatry 2017;79:408-416.

[30] Lokhande RV, Ambekar JG, Bhat KG, Dongre NN. Interleukin-21 and its association with chronic periodontitis. J Indian Soc Periodontol 2019;23:21-24.

[31] Gumus P, Nizam N, Nalbantsoy A, Ozcaka O, Buduneli N. Saliva, Serum Levels of Interleukin-21, - 33 and Prostaglandin E2 in Patients with Generalised Aggressive or Chronic Periodontitis. Oral Health Prev Dent 2017;15:385-390.

[32] Schmitz J, Owyang A, Oldham E, Song Y, Murphy E, McClanahan TK, Zurawski G, Moshrefi M, Qin J, Li X, Gorman DM, Bazan JF, Kastelein RA. IL-33, an interleukin-1-like cytokine that signals via the IL-1 receptor-related protein ST2 and induces T helper type 2-associated cytokines. Immunity 2005;23:479-490.

[33] da Luz FA, Oliveira AP, Borges D, Brigido PC, Silva MJ. The physiopathological role of IL-33: new highlights in bone biology and a proposed role in periodontal disease. Mediators Inflamm 2014;2014:342410.

[34] Saglam M, Koseoglu S, Aral CA, Savran L, Pekbagriyanik T, Cetinkaya A. Increased levels of interleukin-33 in gingival crevicular fluids of patients with chronic periodontitis. Odontology 2017;105:184-190.

[35] Buduneli N, Ozcaka O, Nalbantsoy A. Interleukin-33 levels in gingival crevicular fluid, saliva, or plasma do not differentiate chronic periodontitis. J Periodontol 2012;83:362-368.

[36] Papapanou PN, Sanz M, Buduneli N, Dietrich T, Feres M, Fine DH, Flemmig TF, Garcia R, Giannobile WV, Graziani F, Greenwell $\mathrm{H}$, Herrera D, Kao RT, Kebschull M, Kinane DF, Kirkwood KL, Kocher T, Kornman KS, Kumar PS, Loos BG, Machtei E, Meng H, Mombelli A, Needleman I, Offenbacher S, Seymour GJ, Teles R, Tonetti MS. Periodontitis: Consensus report of workgroup 2 of the 2017 World Workshop on the Classification of Periodontal and Peri-Implant Diseases and Conditions. J Clin Periodontol 2018;45 Suppl 20:S162-S170.

[37] Silness J, Loe H. Periodontal Disease in Pregnancy. Ii. Correlation between Oral Hygiene and Periodontal Condtion. Acta Odontol Scand 1964;22:121-135.

[38] Loe H, Silness J. Periodontal Disease in Pregnancy. I. Prevalence and Severity. Acta Odontol Scand 1963;21:533-551.

[39] Afacan B, Ozturk VO, Emingil G, Kose T, Bostanci N. Alarm antiprotease trappin-2 negatively correlates with proinflammatory cytokines in patients with periodontitis. J Periodontol 2018;89:58-66.

[40] Buduneli N, Kinane DF. Host-derived diagnostic markers related to soft tissue destruction and bone degradation in periodontitis. J Clin Periodontol 2011;38 Suppl 11:85-105.

[41] Wang Z, Chen F, Zhai R, Zhang L, Su L, Lin X, Thompson T, Christiani DC. Plasma neutrophil elastase and elafin imbalance is associated with acute respiratory distress syndrome (ARDS) development. PLoS One 2009;4:e4380.

[42] Into T, Inomata M, Kanno $Y$, Matsuyama T, Machigashira M, Izumi Y, Imamura T, Nakashima M, Noguchi T, Matsushita K. Arginine-specific gingipains from Porphyromonas gingivalis deprive protective functions of secretory leucocyte protease inhibitor in periodontal tissue. Clin Exp Immunol 2006;145:545554.

[43] Yin L, Swanson B, An J, Hacker BM, Silverman GA, Dale BA, Chung WO. Differential effects of periopathogens on host protease inhibitors SLPI, elafin, SCCA1, and SCCA2. J Oral Microbiol 2010;2.

[44] Caucheteux SM, Hu-Li J, Guo L, Bhattacharyya N, Crank M, Collins MT, Paul WE. IL-1beta enhances inflammatory TH2 differentiation. J Allergy Clin Immunol 2016;138:898-901 e894.

[45] Yi JS, Cox MA, Zajac AJ. Interleukin-21: a multifunctional regulator of immunity to infections. Microbes Infect 2010;12:1111-1119.

[46] Mootha A, Malaiappan S, Jayakumar ND, Varghese SS, Toby Thomas J. The Effect of Periodontitis on Expression of Interleukin-21: A Systematic Review. Int J Inflam 2016;2016:3507503.

[47] Dutzan N, Vernal R, Vaque JP, Garcia-Sesnich J, Hernandez M, Abusleme L, Dezerega A, Gutkind JS, Gamonal J. Interleukin-21 expression and its association with proinflammatory cytokines in untreated chronic periodontitis patients. J Periodontol 2012;83:948-954.

[48] Koseoglu S, Hatipoglu M, Saglam M, Enhos S, Esen HH. Interleukin-33 could play an important role in the pathogenesis of periodontitis. J Periodontal Res 2015;50:525-534. 